\title{
MULTIPLE CO-PRIME DIVISORS AND MULTIPLE DIVISORS GRAPHS
}

\author{
HARIWAN FAdHIL M.SAliH and NechiRVAn BADAL IbRAHIM \\ Dept. of Mathematics, College of Science University of Duhok, Kurdistan Region-Iraq.
}

(Received: November 15, 2017; Accepted for publication: December 28, 2017)

\begin{abstract}
In this paper we introduce two new concepts of graphs. Let $R$ be a commutative ring with identity and $Z(R) \backslash\{0\}$ be the set of elements in $R$ divided it into two sets $Z_{1}(R)$ and $Z_{2}(R)$, where $Z_{1}(R)$ be the set of coprime divisor elements satisfies the Euler's function and $Z_{2}(R)$ be the set of non-co-prime divisor elements, a simple graph $M C(R)$ is associated to $Z(R)$ it is called multiple co-prime divisors graph. Moreover, Let $R$ be a commutative ring with identity and $Z^{*}(R)=Z(R) \backslash\{0\}$ be the set of all non-zero divisor elements in $R$, a simple graph $M(R)$ is associated to $R$ for distinct elements a and $b$ in $Z *(R)$ is an edge in $M(R)$ if and only if $a b a=a(\bmod n)$ for all $\mathbf{n}$ in $\mathbf{N}$. Also, diameter, girth, chromatic number and nullity of multiple co-prime divisor and multiple divisor graphs will be determined.
\end{abstract}

KEYWORDS: zero divisor graph, multiple co-prime divisor graphs and multiple divisor graphs.

\section{INTRODUCTION}

A graph is an ordered pair $\mathrm{G}=(\mathrm{V}, \mathrm{E})$, where $\mathrm{V}$ is a nonempty set of vertices and $\mathrm{E}$ the set of edges of $G$. we shall consider $G$ is undirected and finite. A path in $G$ is a sequence $\mathrm{v}_{1}, \mathrm{v}_{2}, \ldots, \mathrm{v}_{\mathrm{n}}$ of vertices where $\mathrm{v}_{\mathrm{i}}$ is adjacent to $\mathrm{v}_{\mathrm{i}+1}$. A graph $\mathrm{G}$ is connected if every two vertices can be joined by a path. The distance between two vertices $\mathrm{u}$ and $\mathrm{v}$ is the minimum of the lengths of all $\mathrm{u}-\mathrm{v}$ paths in $\mathrm{G}$, and is denoted by $\mathrm{d}_{\mathrm{G}}(\mathrm{u}, \mathrm{v})$. If no $u-v$ path exists, we set $d_{G}(u, v)=\infty$. The girth of $G$ is the length of a shortest cycle and is denoted by $\operatorname{gir}(\mathrm{G})$, and the circumference is the length of a longest cycle. Let $\mathrm{G}$ be a simple undirected graph with vertex set $\mathrm{V}=\mathrm{V}(\mathrm{G})$ and edge set $\mathrm{E}=\mathrm{E}(\mathrm{G})$. A graph $\mathrm{G}$ is said to be a singular graph provided that its adjacency matrix $A(G)$ is a singular matrix. Let $\lambda_{1}, \lambda_{2}, \ldots, \lambda_{p}$ be the eigenvalues of a graph $\mathrm{G}$, which they form the spectrum of G. The algebraic multiplicity of the number zero in the spectrum of the graph $G$ is called its nullity (degree of singularity) and denoted by $\eta(G)$ which was studied by Gutman in [2]. The concept of zero divisor graphs $\Gamma(\mathrm{R})$ was introduced by I. Beck in [4] but his motive was in coloring of graphs. In [3], Anderson and Livingston studied the diameter of a graph $\Gamma(\mathrm{R})$ of a commutative ring $\mathrm{R}$ with identity. For undefined terms in graph theory, we refer to [7].

Two vertices $u$ and $v$ in a graph $G$ are said to be coneighbor vertices if and only if $\mathrm{N}_{\mathrm{G}}(\mathrm{u})=\mathrm{N}_{\mathrm{G}}(\mathrm{v})$.

Lemma 1.1:[6] (Coneighbor Lemma) For any pair of coneighbor vertices $u$ and $v$ in a graph $G$, $\eta(G)=\eta(G-u)+1=\eta(G-v)+1$.

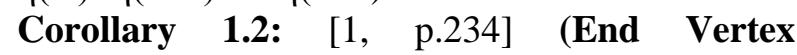
Corollary) If $\mathrm{G}$ is a bipartite graph with an end vertex, and $H$ is an induced subgraph of $G$ obtained by deleting this vertex together with the vertex adjacent to it, then $\eta(G)=\eta(H)$.

\section{THE MULTIPLE CO-PRIME DIVISORS GRAPH OF THE RING R}

In this section, we introduce a new concept of graph and study the properties.

Definition 2.1: Let $\mathrm{R}$ be a commutative ring with identity and $Z(R) \backslash\{0\}$ be the set of elements in $R$ divided it in to two sets $Z_{1}(R)$ and $Z_{2}(R)$, where $Z_{1}(R)$ be the set of co-prime divisor elements satisfies the Euler's function and $Z_{2}(R)$ be the set of non-co-prime divisor elements, a simple graph $\mathrm{MC}(\mathrm{R})$ is associated to $\mathrm{Z}(\mathrm{R})$ where every element in $Z_{1}(R)$ is adjacent to every element in $Z_{2}(R)$ this graph is called multiple co-prime divisors graph. The multiple co-prime divisors graph of the ring $R=Z_{n}, n=p q$ where $p<q$. Notice 
that, in this paper, we assume that $\mathrm{p}<\mathrm{q}$ and $\mathrm{p}, \mathrm{q}$ be prime numbers.

The multiple co-prime divisors set has two sets of vertices $Z_{1}\left(Z_{p q}\right)$ and $Z_{2}\left(Z_{p q}\right)$ the vertices in $Z_{1}\left(Z_{p q}\right)$ of order $(\mathrm{p}-1)(\mathrm{q}-1)$ are non-adjacent and the vertices in $Z_{2}\left(Z_{p q}\right)$ of order $p+q-2$ are nonadjacent, but each vertex in $\mathrm{Z}_{1}\left(\mathrm{Z}_{\mathrm{pq}}\right)$ is adjacent to all vertices in $Z_{2}\left(Z_{p q}\right)$.

Each vertex in $Z_{1}\left(Z_{p q}\right)$ are of degree $(p+q-2)$ and they are non-adjacent with all other vertices of the same set $\mathrm{Z}_{1}\left(\mathrm{Z}_{\mathrm{pq}}\right)$ and each vertex in $\mathrm{Z}_{2}\left(\mathrm{Z}_{\mathrm{pq}}\right)$ are of degree $((\mathrm{p}-1)(\mathrm{q}-1))$ and they are non-adjacent with all other vertices of the same set $\mathrm{Z}_{2}\left(\mathrm{Z}_{\mathrm{pq}}\right)$.

Theorem 2.2: Let $\mathrm{R}=\mathrm{Z}_{\mathrm{pq}}$, then $\mathrm{MC}\left(\mathrm{Z}_{\mathrm{pq}}\right)$ is isomorphic to complete bipartite graph $\quad \mathrm{K}_{(\mathrm{p}-}$ 1)(q-1), $\mathrm{q}+\mathrm{p}-2$.

Proof: According to the two sets of the multiple co-prime divisors graph, $Z_{1}$ and $Z_{2}$, where $Z_{1} . Z_{2} \neq$ 0 , means that are non-adjacent together but $Z_{1}$ and $\mathrm{Z}_{2}$ are adjacent with all other vertices $\mathrm{u}_{\mathrm{i}}, \mathrm{i}=1,2$, $3, \ldots,(\mathrm{p}-1)(\mathrm{q}-1)\left(\mathrm{u}_{\mathrm{i}}\right.$ represented the first type of vertices in $\left.Z_{1}\right)$ and $v_{j}, j=1,2,3, \ldots,(p+q-2)\left(v_{j}\right.$ represented the second type of vertices in $Z_{2}$ ) they are also non adjacent together, $u_{i} \cdot v_{j} \neq 0$, implies that the multiple co-prime divisors graph $\mathrm{MC}\left(\mathrm{Z}_{\mathrm{pq}}\right)$ is complete bipartite graph $\mathrm{K}_{(\mathrm{p}-1)(\mathrm{q}-1), \mathrm{q}+\mathrm{p}-2 \text {. }}$

Proposition 2.3: The diameter of $\left.\mathrm{MC}\left(\mathrm{Z}_{\mathrm{pq}}\right)\right)$ is less than or equal to 2 .

Proof: The multiple co-prime divisors set has two sets of vertices $Z_{1}\left(Z_{p q}\right)$ and $Z_{2}\left(Z_{p q}\right)$, each vertices in $Z_{1}\left(Z_{p q}\right)$ is adjacent to all vertices in $Z_{2}\left(Z_{p q}\right)$, then the shortest path between $u$ and $v$ is of length one, so $\operatorname{diam}(\mathrm{u}, \mathrm{v})=1$, but the vertices in $\mathrm{Z}_{1}\left(\mathrm{Z}_{\mathrm{pq}}\right)$ are non-adjacent, then the shortest path between any two vertices $u$ and $v$ is of length two, so $\operatorname{diam}(u, v)=2$, and the vertices in $Z_{2}\left(Z_{p q}\right)$ are nonadjacent, then the shortest path between any two vertices $u$ and $v$ is of length two, $\operatorname{sodiam}(u, v)=2$. Hence $\operatorname{diam}\left(\mathrm{MC}\left(\mathrm{Z}_{\mathrm{pq}}\right)\right) \leq 2$.

Proposition 2.4: The girth of $\mathrm{MC}\left(\mathrm{Z}_{\mathrm{pq}}\right)$ is equal to 4.

Proof: The set of the multiple co-prime divisors graph $\mathrm{MC}\left(\mathrm{Z}_{\mathrm{pq}}\right)$ is $\mathrm{Z}_{1}\left(\mathrm{Z}_{\mathrm{pq}}\right)$ Let $\mathrm{u}_{1}, \mathrm{u}_{2}, \mathrm{u}_{3}, \ldots, \mathrm{u}_{\mathrm{i}}, \mathrm{i}=1$, $2,3, \ldots,(p-1)(q-1)\left(u_{i}\right.$ represented the first type of vertices in $Z_{1}$ ) and $v_{1}, v_{2}, v_{3}, \ldots, v_{j}, j=1,2,3, \ldots$, $(p+q-2)\left(v_{j}\right.$ represented the second type of vertices in $\mathrm{Z}_{2}$ ) respectively. Then all the cycles in the graph $\mathrm{MC}\left(\mathrm{Z}_{\mathrm{pq}}\right)$ are of length 4 , they are the smallest and they are of the form $\mathrm{u}_{1} \rightarrow \mathrm{v}_{1} \rightarrow \mathrm{u}_{2} \rightarrow$ $\mathrm{v}_{2} \rightarrow \mathrm{u}_{1}$. Then the girth is equal to 4 .

Proposition 2.5: The chromatic number of $\operatorname{MC}\left(Z_{\mathrm{pq}}\right)$ is equal to $(\mathrm{p}-1)(\mathrm{q}-1)$.

Proof: Since no two adjacent vertices take the same color in coloring vertices in any graph, then each vertex in $Z_{1}$ have the different color and all other vertices $\mathrm{u}_{\mathrm{i}}, \mathrm{i}=1,2, \ldots,(\mathrm{p}-1)(\mathrm{q}-1)$ which represent the vertices in $\mathrm{Z}_{1}$ has another color. Therefore the total number of colors used in the coloration of this graph is (p-1)(q-1), implies that the chromatic number is $(\mathrm{p}-1)(\mathrm{q}-1)$.

Proposition 2.6: The multiple co-prime divisors graph of $Z_{\mathrm{qp}}$ is star graph $\mathrm{S}_{1, \mathrm{p}+\mathrm{q}-2}$, by removing the (pq-p-q) from vertices of $Z_{1}\left(Z_{p q}\right)$.

Proof: The vertices in the multiple co-prime divisors graph are two sets of vertices $Z_{1}\left(Z_{p q}\right)$ and $\mathrm{Z}_{1}\left(\mathrm{Z}_{\mathrm{pq}}\right)$ the first set from 1 to $(\mathrm{p}-1)(\mathrm{q}-1)$ and the second set from 1 to $\mathrm{p}+\mathrm{q}-2$, where each vertices in $\mathrm{Z}_{1}\left(\mathrm{Z}_{\mathrm{pq}}\right)$ are of degree $(\mathrm{p}+\mathrm{q}-2)$ and they are nonadjacent with all other vertices of the same set $\mathrm{Z}_{1}\left(\mathrm{Z}_{\mathrm{pq}}\right)$, therefore, when we remove all the vertices in $Z_{1}\left(Z_{p q}\right)$ except a vertex, say $u_{1}$, then we get the star graph of the form $S_{1, p+q-2}$.

Theorem 2.7: The nullity of $\operatorname{MC}\left(Z_{p q}\right)$ is equal to pq-4.

Proof: In the $\operatorname{MC}\left(Z_{\mathrm{pq}}\right)$ ), we have two sets of coneighbor vertices, by using Lemma 1.1 , we get: $\eta\left(\mathrm{MC}\left(\mathrm{Z}_{\mathrm{pq}}\right)\right)=$ $1+\eta\left(\mathrm{MC}\left(\mathrm{K}_{2}\right)\right)=\mathrm{pq}-4+\eta\left(\mathrm{MC}\left(\mathrm{K}_{2}\right)\right)$ $(\mathrm{p}-1)(\mathrm{q}-1)-1+\mathrm{q}+\mathrm{p}-2-$ $\eta\left(\mathrm{MC}\left(\mathrm{K}_{2}\right)\right)=0$. Hence, $\eta\left(\mathrm{MC}\left(\mathrm{Z}_{\mathrm{pq}}\right)\right)=\mathrm{pq}-4$.

The multiple co-prime divisors graph of the ring $Z_{n}, n=p^{2} q$ where $p=2<q$.

The multiple co-prime divisors set has two sets of vertices $Z_{1}(R)$ and $Z_{2}(R)$ the vertices in $Z_{1}\left(Z_{p}^{2}\right)$ of order $\mathrm{pq}+5$ are non-adjacent and the vertices in $\mathrm{Z}_{2}\left(\mathrm{Z}_{\mathrm{p} q}^{2}\right)$ of order $2 \mathrm{p}(\mathrm{q}-1)$ are non-adjacent, but each vertex in $Z_{1}\left(Z_{p q}^{2}\right)$ is adjacent to all vertices in $Z_{2}\left(Z_{p q}^{2}\right)$, each vertex in $Z_{1}\left(Z_{p q}^{2}\right)$ are of degree $2 \mathrm{p}(\mathrm{q}-1)$ and they are non-adjacent with all other vertices of the same set $Z_{1}\left(Z_{p q}^{2}\right)$ and each vertex in $\mathrm{Z}_{2}\left(\mathrm{Z}_{\mathrm{pq}}^{2}\right)$ are of degree $(\mathrm{pq}+5)$ and they are nonadjacent with all other vertices of the same set $\mathrm{Z}_{2}\left(\mathrm{Z}_{\mathrm{p} \mathrm{q}}^{2}\right)$. 
Theorem 2.8: Let $\mathrm{R}=\mathrm{Z}_{\mathrm{p} q}^{2}$, where $\mathrm{p}=2<\mathrm{q}$, then $\mathrm{MC}\left(\mathrm{Z}_{\mathrm{p} \mathrm{q}}^{2}\right)$ is isomorphic to complete bipartite graph $\mathrm{K}_{\mathrm{pq}+5,2 \mathrm{p}(\mathrm{q}-1)}$.

Proof: According to the two sets of the multiple co-prime divisors graph, $Z_{1}$ and $Z_{2}$, where $Z_{1} . Z_{2} \neq$ 0 , means that are non-adjacent together but $Z_{1}$ and $\mathrm{Z}_{2}$ are adjacent with all other vertices $\mathrm{u}_{\mathrm{i}}, \mathrm{i}=1,2$, $3, \ldots, p q+5 \quad\left(u_{i}\right.$ represented the first type of vertices in $\left.Z_{1}\right)$ and $v_{j}, j=1,2,3, \ldots, 2 p(q-1)\left(v_{j}\right.$ represented the second type of vertices in $Z_{2}$ ) they are also non adjacent together, $\mathrm{u}_{\mathrm{i}} \cdot \mathrm{v}_{\mathrm{j}} \neq 0$, implies that the multiple co-prime divisors graph $\operatorname{MC}\left(Z_{p q}^{2}\right)$ is complete bipartite graph $\mathrm{K}_{\mathrm{pq}+5,2 \mathrm{p}(\mathrm{q}-1)}$. Proposition 2.9: The diameter of $M C\left(Z_{p q}^{2}\right)$ ) is less than or equal to 2.

Proof: The multiple co-prime divisors set has two sets of vertices $Z_{1}\left(Z_{p q}^{2}\right)$ and $Z_{2}\left(Z_{p q}^{2}\right)$, each vertices in $\mathrm{Z}_{1}\left(\mathrm{Z}_{\mathrm{p} \mathrm{q}}^{2}\right)$ is adjacent to all vertices in $\mathrm{Z}_{2}\left(\mathrm{Z}_{\mathrm{pq}}^{2}\right)$, then the shortest path between $u$ and $v$ is of length one, so $\operatorname{diam}(\mathrm{u}, \mathrm{v})=1$, but the vertices in $\mathrm{Z}_{1}\left(\mathrm{Z}_{\mathrm{p} \mathrm{q}}^{2}\right)$ are non-adjacent, then the shortest path between any two vertices $u$ and $v$ is of length two, so $\operatorname{diam}(\mathrm{u}, \mathrm{v})=2$, and the vertices in $\mathrm{Z}_{2}\left(\mathrm{Z}_{\mathrm{p}}{ }_{\mathrm{q}}\right)$ are nonadjacent, then the shortest path between any two vertices $u$ and $v$ is of length two, $\operatorname{sodiam}(u, v)=2$. Hence, $\operatorname{diam}\left(\mathrm{MC}\left(\mathrm{Z}_{\mathrm{p} \mathrm{q}}^{2}\right)\right) \leq 2$.

Proposition 2.10: The girth of $\mathrm{MC}\left(\mathrm{Z}_{\mathrm{p} q}^{2}\right)$ is equal to 4 .

Proof: The set of the multiple co-prime divisors graph $\mathrm{MC}\left(\mathrm{Z}_{\mathrm{p} \mathrm{q}}^{2}\right)$ is $\mathrm{Z}_{1}\left(\mathrm{Z}_{\mathrm{pq}}^{2}\right)$ Let $\mathrm{u}_{1}, \mathrm{u}_{2}, \mathrm{u}_{3}, \ldots, \mathrm{u}_{\mathrm{i}}$, $i=1,2,3, \ldots, p q+5\left(u_{i}\right.$ represented the first type of vertices in $\left.Z_{1}\right)$ and $v_{1}, v_{2}, v_{3}, \ldots, v_{j}, j=1,2,3, \ldots$, $2 p(q-1)\left(v_{j}\right.$ represented the second type of vertices in $Z_{2}$ ) respectively. Then all the cycles in the graph $\operatorname{MC}\left(Z_{p q}^{2}\right)$ are of length 4 , they are the smallest and they are of the form $\mathrm{u}_{1} \rightarrow \mathrm{v}_{1} \rightarrow \mathrm{u}_{2} \rightarrow$ $\mathrm{v}_{2} \rightarrow \mathrm{u}_{1}$. Then the girth is equal to 4 .

Proposition 2.11: The chromatic number of $\operatorname{MC}\left(Z_{\mathrm{p} \mathrm{q}}^{2}\right)$ is equal to 2 .

Proof: Since no two adjacent vertices take the same color in coloring vertices in any graph, then each vertex in $Z_{1}$ have the same color and each vertex in $Z_{2}$ have the same color. Therefore the total number of colors used in the coloration of this graph is 2, implies that the chromatic number of $\mathrm{MC}\left(\mathrm{Z}_{\mathrm{pq}}^{2}\right)$ is equal to 2 .
Proposition 2.12: The multiple co-prime divisors graph of $Z_{p q}^{2}$ is star graph $S_{1,2 p(q-1)}$, by removing the $\mathrm{pq}+4$ vertices from $\mathrm{Z}_{1}\left(\mathrm{Z}_{\mathrm{pq}}^{2}\right)$.

Proof: The vertices in the multiple co-prime divisors graph are two sets of vertices $Z_{1}\left(Z_{p q}^{2}\right)$ and $Z_{1}\left(Z_{p q}^{2}\right)$ the first set from 1 to $p q+5$ and the second set from 1 to $p+q-2$, where each vertex in $\mathrm{Z}_{1}\left(\mathrm{Z}_{\mathrm{p} q}^{2}\right)$ are of degree $2 \mathrm{p}(\mathrm{q}-1)$ and they are nonadjacent with all other vertices of the same set $\mathrm{Z}_{1}\left(\mathrm{Z}_{\mathrm{p} q}^{2}\right)$, therefore when we remove all the vertices in $Z_{1}\left(Z_{p q}^{2}\right)$ except a vertex, say $u_{1}$, then we get the star graph $S_{1,2 p(q-1)}$.

Theorem 2.13: The nullity of $\mathrm{MC}\left(\mathrm{Z}_{\mathrm{p} \mathrm{q}}^{2}\right)$ is equal to $6 \mathrm{q}-1$, where $\mathrm{p}=2<\mathrm{q}$.

Proof: In the $\operatorname{MC}\left(\mathrm{Z}_{\mathrm{pq}}^{2}\right)$ ), we have two sets of coneighbor vertices, by using Lemma 1.1, we get: $\eta\left(\mathrm{MC}\left(\mathrm{Z}_{\mathrm{p} \mathrm{q}}^{2}\right)\right)=\quad \mathrm{pq}+5+2 \mathrm{p}(\mathrm{q}-1)-2+\eta\left(\mathrm{K}_{2}\right)=3 \mathrm{pq}-$ $2 \mathrm{p}+3+\eta\left(\mathrm{K}_{2}\right)$ and $\eta\left(\mathrm{K}_{2}\right)=0$. Hence, $\eta\left(\mathrm{MC}\left(\mathrm{Z}_{2}^{2}{ }_{\mathrm{q}}\right)\right)=$ $6 \mathrm{q}-1$.

The multiple co-prime divisors graph of the ring $Z_{n}, n=p q r$ where $p=2<q=3<r$.

The multiple co-prime divisors set has two sets of vertices $Z_{1}(R)$ and $Z_{2}(R)$ the vertices in $Z_{1}\left(Z_{p q r}\right)$ of order $2 \mathrm{r}-2$ are non-adjacent and the vertices in $\mathrm{Z}_{2}\left(\mathrm{Z}_{\mathrm{pqr}}\right)$ of order $\mathrm{r}(\mathrm{q}+1)+1$ are non-adjacent, but each vertex in $Z_{1}\left(Z_{p q r}\right)$ is adjacent to all vertices in $\mathrm{Z}_{2}\left(\mathrm{Z}_{\mathrm{pqr}}\right)$, each vertex in $\mathrm{Z}_{1}\left(\mathrm{Z}_{\mathrm{pqr}}\right)$ are of degree $(\mathrm{p}+\mathrm{q}-2)$ and they are non-adjacent with all other vertices of the same set $Z_{1}\left(Z_{\mathrm{pqr}}\right)$ and each vertex in $\mathrm{Z}_{2}\left(\mathrm{Z}_{\mathrm{pqr}}\right)$ are of degree $(2 \mathrm{r}-2)$ and they are nonadjacent with all other vertices of the same set $\mathrm{Z}_{2}\left(\mathrm{Z}_{\mathrm{pqr}}\right)$.

Theorem 2.14: Let $\mathrm{R}=\mathrm{Z}_{\mathrm{pqr}}$, where $\mathrm{p}<\mathrm{q}$, then $\mathrm{MC}\left(Z_{\mathrm{pqr}}\right)$ is isomorphic to complete bipartite graph $K_{2 \mathrm{r}-2, \mathrm{r}(\mathrm{q}+1)+1}$.

Proof: According to the two sets of the multiple co-prime divisors graph, $Z_{1}$ and $Z_{2}$, where $Z_{1} . Z_{2} \neq$ 0 , means that are non-adjacent together but $Z_{1}$ and $\mathrm{Z}_{2}$ are adjacent with all other vertices $\mathrm{u}_{\mathrm{i}}, \mathrm{i}=1,2$, $3, \ldots, 2 r-2\left(u_{i}\right.$ represented the first type of vertices in $\left.\mathrm{Z}_{1}\right)$ and $\mathrm{v}_{\mathrm{j}}, \mathrm{j}=1,2,3, \ldots, \mathrm{r}(\mathrm{q}+1)+1\left(\mathrm{v}_{\mathrm{j}}\right.$ represented the second type of vertices in $Z_{2}$ ) they are also non adjacent together, $\mathrm{u}_{\mathrm{i}} \cdot \mathrm{v}_{\mathrm{j}} \neq 0$, implies that the multiple co-prime divisors graph $\mathrm{MC}\left(\mathrm{Z}_{\mathrm{pqr}}\right)$ is complete bipartite graph $\mathrm{K}_{2 \mathrm{r}-2, \mathrm{r}(\mathrm{q}+1)+1}$.

Proposition 2.15: The girth of $\mathrm{MC}\left(\mathrm{Z}_{\mathrm{pqr}}\right)$ is equal to 4 . 
Proof: The set of the multiple co-prime divisors graph $\mathrm{MC}\left(\mathrm{Z}_{\mathrm{pqr}}\right)$ is $\mathrm{Z}_{1}\left(\mathrm{Z}_{\mathrm{pqr}}\right)$ Let $\mathrm{u}_{1}, \mathrm{u}_{2}, \mathrm{u}_{3}, \ldots, \mathrm{u}_{\mathrm{i}}$, $\mathrm{i}=1,2,3, \ldots, 2 \mathrm{r}-2\left(\mathrm{u}_{\mathrm{i}}\right.$ represented the first type of vertices in $\left.Z_{1}\right)$ and $v_{1}, v_{2}, v_{3}, \ldots, v_{j}, j=1,2,3, \ldots$, $\mathrm{r}(\mathrm{q}+1)+1 \quad\left(\mathrm{v}_{\mathrm{j}}\right.$ represented the second type of vertices in $Z_{2}$ ) respectively. Then all the cycles in the graph $\mathrm{MC}\left(Z_{\mathrm{pqr}}\right)$ are of length 4 , they are the smallest and they are of the form $\mathrm{u}_{1} \rightarrow \mathrm{v}_{1} \rightarrow \mathrm{u}_{2} \rightarrow$ $v_{2} \rightarrow u_{1}$. Then the girth is equal to 4 .

Proposition 2.16: The chromatic number of $\mathrm{MC}\left(\mathrm{Z}_{\mathrm{pqr}}\right)$ is equal to 2 .

Proof: The multiple co-prime divisors graph $\mathrm{MC}\left(\mathrm{Z}_{\mathrm{pqr}}\right)$ is isomorphic to complete bipartite graph $\mathrm{K}_{2 \mathrm{r}-2, \mathrm{r}(\mathrm{q}+1)+1}$. Then the chromatic number of $\mathrm{MC}\left(\mathrm{Z}_{\mathrm{pqr}}\right)$ is equal to 2 .

Proposition 2.17: The diameter of $\left.\mathrm{MC}\left(\mathrm{Z}_{\mathrm{pqr}}\right)\right)$ is less than or equal to 2 .

Proof: The multiple co-prime divisors set has two sets of vertices $Z_{1}\left(Z_{\mathrm{pqr}}\right)$ and $Z_{2}\left(Z_{\mathrm{pqr}}\right)$, each vertices in $Z_{1}\left(Z_{\mathrm{pqr}}\right)$ is adjacent to all vertices in $Z_{2}\left(Z_{\mathrm{pqr}}\right)$, then the shortest path between $u$ and $v$ is of length one, so $\operatorname{diam}(\mathrm{u}, \mathrm{v})=1$, but the vertices in $\mathrm{Z}_{1}\left(\mathrm{Z}_{\mathrm{pqr}}\right)$ are non-adjacent, then the shortest path between any two vertices $\mathrm{u}$ and $\mathrm{v}$ is of length two, so $\operatorname{diam}(\mathrm{u}, \mathrm{v})=2$, and the vertices in $\mathrm{Z}_{2}\left(\mathrm{Z}_{\mathrm{pqr}}\right)$ are nonadjacent, then the shortest path between any two vertices $u$ and $v$ is of length two, so $\operatorname{diam}(u, v)=2$. Hence, $\operatorname{diam}\left(\mathrm{MC}\left(\mathrm{Z}_{\mathrm{pqr}}\right)\right) \leq 2$.

Proposition 2.18: The multiple co-prime divisors graph of $Z_{\mathrm{pqr}}$ is star graph $\mathrm{S}_{1, \mathrm{r}(\mathrm{q}+1)+1}$, by removing the (2r-3) vertices from the vertices of $Z_{1}\left(Z_{p q r}\right)$.

Proof: The vertices in the multiple co-prime divisors graph are two sets of vertices $Z_{1}\left(Z_{p q r}\right)$ and $\mathrm{Z}_{1}\left(\mathrm{Z}_{\mathrm{pqr}}\right)$ the first set from 1 to $2 \mathrm{r}-2$ and the second set from 1 to $r(q+1)+1$, where each vertices in $\mathrm{Z}_{1}\left(\mathrm{Z}_{\mathrm{pqr}}\right)$ are of degree $\mathrm{r}(\mathrm{q}+1)+1$ and they are nonadjacent with all other vertices of the same set $\mathrm{Z}_{1}\left(\mathrm{Z}_{\mathrm{pqr}}\right)$, therefore, when we remove all the vertices in $Z_{1}\left(Z_{p q r}\right)$ except a vertex, say $u_{1}$, then we get the star graph $S_{1, \mathrm{r}(q+1)+1}$.

Theorem 2.19: The nullity of $\mathrm{MC}\left(\mathrm{Z}_{\mathrm{pqr}}\right)$ is equal to $\mathrm{r}(\mathrm{q}+3)-3$, where $\mathrm{p}=2<\mathrm{q}=3<\mathrm{r}$.

Proof: In the $\operatorname{MC}\left(Z_{\mathrm{pqr}}\right)$, we have two sets of coneighbor vertices, by using Lemma 1.1, we get: $\eta\left(\mathrm{MC}\left(\mathrm{Z}_{\mathrm{pqr}}\right)\right)=2 \mathrm{r}-2+\mathrm{rq}+\mathrm{r}+1-2+\eta\left(\mathrm{K}_{2}\right)=3 \mathrm{r}+\mathrm{rq}-$ $3+\eta\left(\mathrm{K}_{2}\right)$ and $\eta\left(\mathrm{K}_{2}\right)=0$.

Hence,

\section{THE MULTIPLE DIVISORS GRAPH OF THE RING $R$}

In this section, we introduce the new concept of graph and study the properties.

Definition 3.1: Let $R$ be a commutative ring with identity and $Z^{*}(\mathrm{R})=\mathrm{Z}(\mathrm{R}) /\{0\}$ be the set of all non-zero zero divisor elements in $\mathrm{R}$, a simple graph $M(R)$ is associated to $R$ for distinct elements $a$ and $b$ in $Z^{*}(R)$ is an edge in $M(R)$ if and only if $a b a=a(\bmod n)$ for all $n$ in $N$, this graph is called multiple divisor graphs.

The multiple divisors graph of the $\operatorname{ring} Z_{n}$, $\mathrm{n}=\mathrm{pq}$ where $\mathrm{p}=\mathbf{2}<\mathrm{q}$.

The multiple divisor graph of $\mathrm{Z}_{\mathrm{pq}}$, where $\mathrm{p}=2<$ $\mathrm{q}$ has the following properties:

1- The vertex set of multiple divisor graph of $Z_{p q}$ is $\mathrm{V}\left(\mathrm{M}\left(\mathrm{Z}_{\mathrm{pq}}\right)\right)=\left\{\mathrm{v}_{\mathrm{i}}, \mathrm{i}=1,2, \ldots, \mathrm{pq}-1\right\}$.

2- The order and size of the multiple divisor graph of $Z_{\mathrm{pq}}$ are (pq-1) and (( $\left.\left.2 \mathrm{pq}+3 \mathrm{q}-11\right) / 2\right)$,

respectively.

3- The vertex $\mathrm{v}_{1}$ adjacent to all vertices in $\mathrm{M}\left(\mathrm{Z}_{\mathrm{pq}}\right)$ and $\operatorname{deg}\left(\mathrm{v}_{1}\right)=\mathrm{pq}-2$.

4- The vertex $v_{q}$ adjacent to $q-3 / 2$ odd vertices less than $\mathrm{v}_{\mathrm{q}-1}$ and $\operatorname{deg}\left(\mathrm{v}_{\mathrm{q}}\right)=\mathrm{q}-1 / 2$.

5- The vertex $\mathrm{v}_{\mathrm{q}-1}$ adjacent to even vertices greater than $\mathrm{v}_{\mathrm{q}}$ and $\operatorname{deg}\left(\mathrm{v}_{\mathrm{q}-1}\right)=\mathrm{q}+1 / 2$.

6- The vertex $\mathrm{v}_{\mathrm{q}+1}$ adjacent to even vertices greater than $\mathrm{v}_{\mathrm{q}+1}$ and $\operatorname{deg}\left(\mathrm{v}_{\mathrm{q}+1}\right)=\mathrm{q}+1 / 2$.

7- The multiple divisors graph of $Z_{p q}$ have $q-2$ coneighbor vertices of degree one (q-2 end vertices).

8- The even vertices less than $\mathrm{v}_{\mathrm{q}-1}$ are nonadjacent and of degree one.

9- The odd vertices greater than $\mathrm{v}_{\mathrm{q}+1}$ are nonadjacent and of degree one.

10- The vertices in (8) and (9) are non-adjacent vertices.

Theorem 3.2: Let $\mathrm{R}=\mathrm{Z}_{\mathrm{pq}}$, where $\mathrm{p}<\mathrm{q}$, then $\mathrm{M}\left(\mathrm{Z}_{\mathrm{pq}}\right)$ is 3-partite.

Proof: The vertex set of multiple divisor graph of $\mathrm{Z}_{\mathrm{pq}}$ can be partitioned into three sets $\mathrm{V}_{1}=\left\{\mathrm{v}_{1}\right\}$, $\mathrm{V}_{2}=\left\{\mathrm{v}_{\mathrm{q}}, \mathrm{v}_{\mathrm{q}+1}\right.$ and all other vertices of degree one $\}$ and $\mathrm{V}_{3}=\left\{\mathrm{v}_{\mathrm{q}-1}\right.$ and the vertices adjacent to $\left.\mathrm{v}_{\mathrm{q}}\right\}$. The vertices in each vertex set are non-adjacent. Clearly the multiple divisor graph of $Z_{p q}$ is 3partite graphs.

Proposition 3.3: The diameter of $\mathrm{M}\left(\mathrm{Z}_{\mathrm{pq}}\right)$ ) is less than or equal to 2 . 
Proof: The vertex set of multiple divisor graph of $\mathrm{Z}_{\mathrm{pq}}$ can be partitioned into three sets $\mathrm{V}_{1}=\left\{\mathrm{v}_{1}\right\}$, $\mathrm{V}_{2}=\left\{\mathrm{v}_{\mathrm{q}}, \mathrm{v}_{\mathrm{q}+1}\right.$ and all other vertices of degree one $\}$ and $\mathrm{V}_{3}=\left\{\mathrm{v}_{\mathrm{q}-1}\right.$ and the vertices adjacent to $\left.\mathrm{v}_{\mathrm{q}}\right\}$, then the shortest path between vertex $\mathrm{V}_{1}$ with $\mathrm{V}_{2}$ and $\mathrm{V}_{3}$ is of length one, but the distance between vertices in set $\mathrm{V}_{2}$ with vertices in set $\mathrm{V}_{3}$ is of length two, then $\operatorname{diam}\left(\mathrm{M}\left(\mathrm{Z}_{\mathrm{pq}}\right)\right) \leq 2$.

Proposition 3.4: The girth of $M\left(Z_{p q}\right)$ is equal to 3 .

Proof: The set of the multiple divisors graph $\mathrm{M}\left(\mathrm{Z}_{\mathrm{pq}}\right)$ is $\mathrm{V}\left(\mathrm{M}\left(\mathrm{Z}_{\mathrm{pq}}\right)\right)=\left\{\mathrm{v}_{\mathrm{i}}, \mathrm{i}=1,2, \ldots, \mathrm{pq}-1\right\}$. Then all the cycles in the graph $\mathrm{M}\left(\mathrm{Z}_{\mathrm{pq}}\right)$ are of length 3 or 4, they are the smallest and they are of the form $\mathrm{v}_{1} \rightarrow \mathrm{v}_{\mathrm{q}-1} \rightarrow \mathrm{v}_{\mathrm{q}+1} \rightarrow \mathrm{v}_{1}$. Then the girth is 3 .

Proposition 3.5: The chromatic number of $\mathrm{M}\left(\mathrm{Z}_{\mathrm{pq}}\right)$ is equal to 3 .

Proof: The vertex set of multiple divisor graph of $Z_{\mathrm{pq}}$ is 3-partite sets, then each set have different color. Hence the chromatic number of $\mathrm{M}\left(\mathrm{Z}_{\mathrm{pq}}\right)$ is equal to 3 .

Proposition 3.6: The multiple divisors graph of $Z_{\mathrm{qp}}$ is star graph $\mathrm{S}_{1, \mathrm{pq}-5}$, by removing the vertices $\mathrm{v}_{\mathrm{q}-1}, \mathrm{v}_{\mathrm{q}}$ and $\mathrm{v}_{\mathrm{q}+1}$ of $\mathrm{M}\left(\mathrm{Z}_{\mathrm{pq}}\right)$.

Proof: The proof is similar to the proof of Proposition 2.18.

Theorem 3.7: The nullity of $\mathrm{M}\left(\mathrm{Z}_{\mathrm{pq}}\right)$ is equal to $2 \mathrm{q}-2$, where $\mathrm{p}=2<\mathrm{q}$.

Proof: In the $\mathrm{M}\left(\mathrm{Z}_{2.3}\right)$, we have 2 coneighbor vertices adjacent with $\mathrm{v}_{1}$, by using Lemma 1.1 and Corollary 1.2, then $\left.\eta\left(\mathrm{M}\left(\mathrm{Z}_{6}\right)\right)=1+\eta\left(\mathrm{K}_{2}\right)\right)=1$ and in the $\mathrm{M}\left(Z_{2.5}\right)$, we have 3 coneighbor vertices adjacent with $\mathrm{v}_{1}$, by using Coneighbor Lemma and end vertex corollary, then $\eta\left(\mathrm{M} \quad\left(\mathrm{Z}_{10}\right)\right)=$ $2+\eta\left(K_{2}\right)+\eta\left(K_{3}\right)=2$. If $q>5$, in the $M\left(Z_{p q}\right)$, we have $\mathrm{q}-2$ coneighbor vertices adjacent with $\mathrm{v}_{1},((\mathrm{q}-3) / 2)$ coneighbor vertices adjacent with $\mathrm{v}_{1}$ and $\mathrm{v}_{\mathrm{q}}$, and ((q-3)/2) coneighbor vertices adjacent with $\mathrm{v}_{1}$ and $\mathrm{v}_{\mathrm{q}-1}$ and $\mathrm{v}_{\mathrm{q}+1}$, by using Lemmas 1.1 and Corollary 1.2, we get: $\eta\left(\mathrm{M}\left(\mathrm{Z}_{\mathrm{pq}}\right)\right)=\mathrm{q}-3+((\mathrm{q}-3) / 2)+((\mathrm{q}-3) / 2)$ $-2+\eta\left(\mathrm{K}_{2}\right)+\eta\left(\mathrm{K}_{3}\right)=2 \mathrm{q}-2+$ and $\eta\left(\mathrm{K}_{2}\right)=\eta\left(\mathrm{K}_{3}\right)=0$.

Hence, $\eta\left(\mathrm{M}\left(\mathrm{Z}_{\mathrm{pq}}\right)\right)=2 \mathrm{q}-2$.

\section{Question:}

1- Construct $\operatorname{MC}\left(Z_{p_{q}}^{2}\right)$ and find properties.

2- Construct $M\left(Z_{p q}{ }^{2}\right)$ and find properties.

3- Construct $M\left(Z_{p q r}\right)$ and find properties.

\section{REFERENCES}

- Cvetkovic', D.M., Doob, M. and Sachs, H.; (1979), Spectra of Graphs-Theory and Application, Academic Press, New York.

- Dragoš M. Cvetkovič and Ivan M. Gutman (1972), The algebraic multiplicity of the number zero in the spectrum of a bipartite graph. Matematički Vesnik (Beograd), vol. 9, pp. 141-150.

- D.D. Andersen and P. S. Livingston "The zero divisor graph of a commutative ring". J. Algebra 217 (1999), pp. 434-447.

- I. Beck, "Coloring of commutative ring". J. Algebra 116 (1988), pp. 208-226.

- Nazar H. Shuker and Husam Q. Mohammad, The Zero Divisor Graph of $\mathrm{Zp}^{\mathrm{n}} \mathrm{q}$, International Journal of Algebra, Vol. 6, 2012, no. 22, 1049 1055.

- Nazar H. Shuker, Payman A. Rashed, The zero divisor graph of the ring $\mathrm{Z}_{\mathrm{pqr}}$, International Journal of Scientific \& Engineering Research, ISSN 2229-5518, Volume 6, Issue 2, February2015.

- N. B. Ibrahim, On the nullity of some sequential element identified, element introduced graphs, MSc thesis, University of Zakho.

- R. Balakrishnan, and K. Ranganathan; (2012), A Textbook of Graph Theory, Springer, New York. 